\title{
ERRATUM
}

\section{Welfare Politics in Congress}

\section{Mead, Lawrence M.}

doi:10.1017/S104909651100031X, published by Cambridge University Press April 8, 2011.

Figures $3-5$ were printed incorrectly on pp. 351-52 of the above publication. The correct figures, titles, and captions, are presented below.

\section{Figure 3}

Incidence of Issue Types as Lead Issue, by Stage of

Welfare Reform, 1962-96

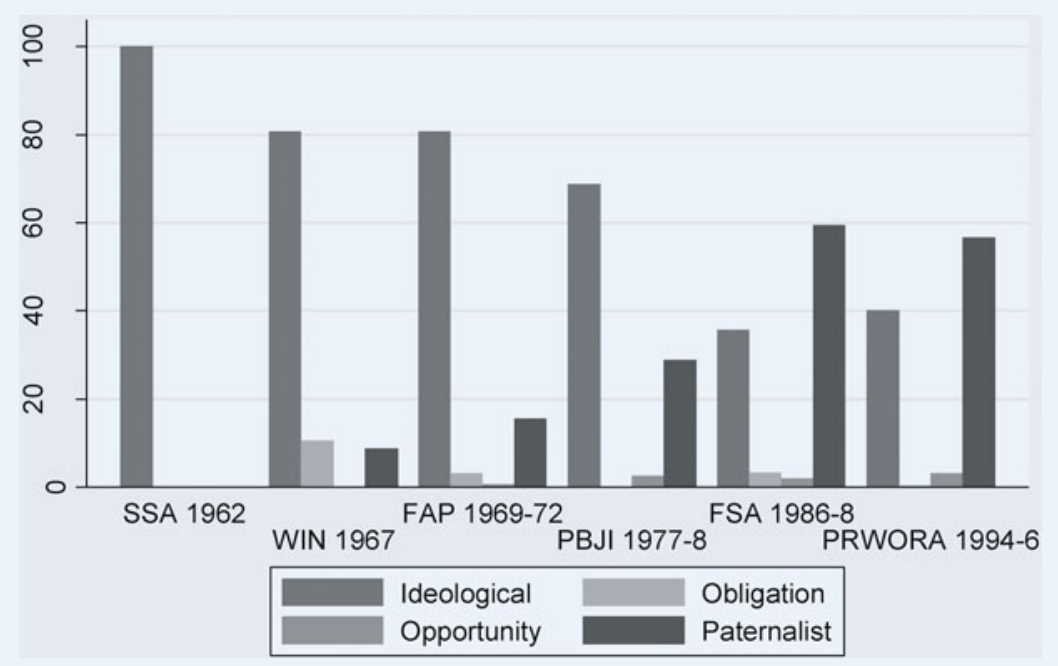

Figure 4

Liberalism of Witnesses Citing Issue Types, by Stage of Welfare Reform, 1962-96

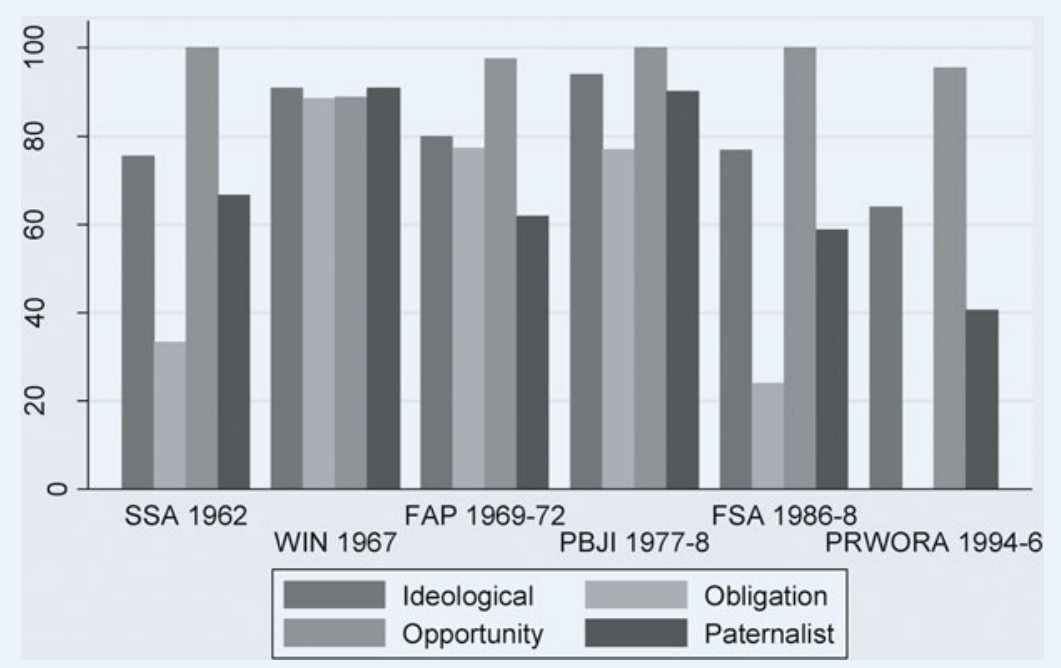




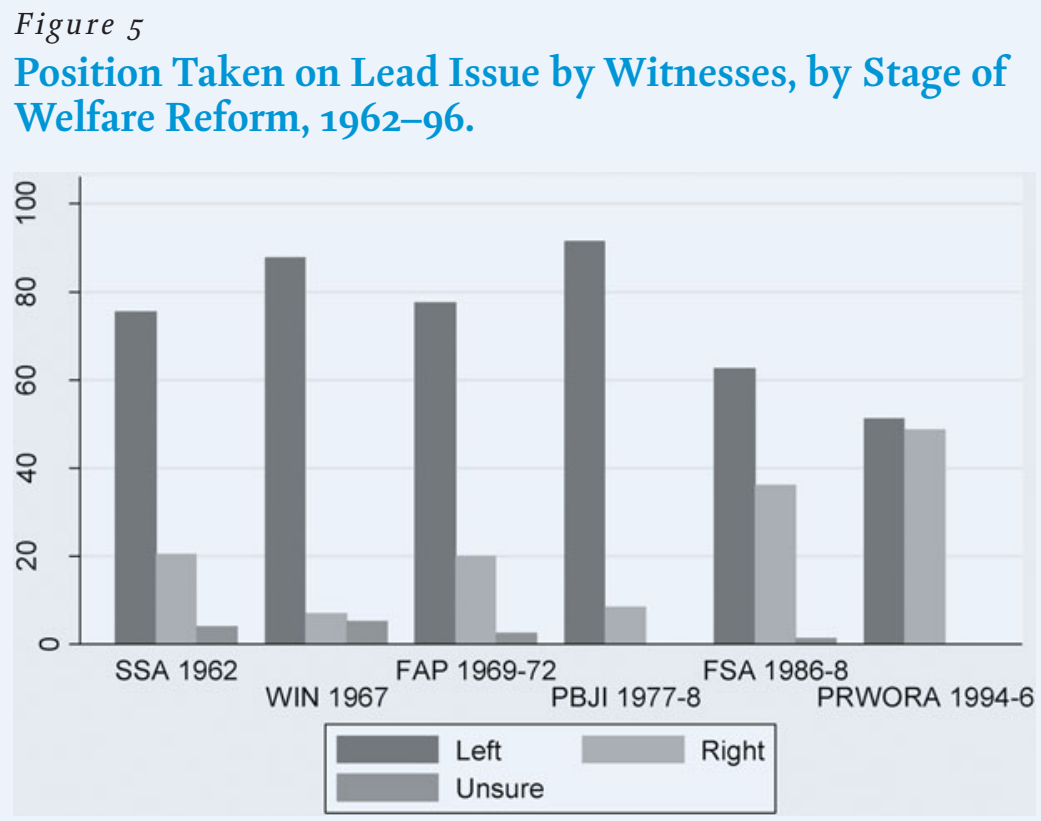

The corrected version of the paper can be found on the Cambridge Journals Online site, at https://journals.cambridge.org/action/ displayFulltext type $=1 \&$ pdftype $=1 \&$ fid $=8253756 \&$ jid $=$ PSC\&volumeId $=44 \&$ issueId $=\&$ aid $=8253754$.

\section{REFEREN C E}

Mead, Lawrence M. 2011. "Welfare Politics in Congress." PS: Political Science and Politics 44 (2): 345-56. 